\title{
Introduction to the Special Issue. Migration, food and agriculture: Insights into what we eat and how our food is produced at the beginning of the third millennium
}

\author{
Yoan Molinero-Gerbeau ${ }^{1 *}$, Monica Șerban ${ }^{2}$, Alin Croitoru ${ }^{3}$ \\ ${ }^{1}$ University Institute for the Study of Migrations (IUEM), Comillas Pontifical University, Calle Alberto Aguilera, \\ 23, 28015 Madrid, Spain. \\ ${ }^{2}$ Research Institute for Quality of Life (ICCV), Romanian Academy, Casa Academiei Române, Calea 13 Septembrie, \\ 13, Sector 5, 05071 Bucharest, Romania. \\ 3 'Lucian Blaga' University of Sibiu, Center for Social Research, 2A Lucian Blaga Street, 550169 Sibiu, Romania.
}

Locking us into our homes, the current COVID 19 pandemic has made us all more conscious of the importance of food in our lives and our food consumption practices. The unprecedented measures restricting international mobility have shown up the complex system of movements behind the production of our food and, bringing the topic to the light, have made us aware of the conditions of farmworkers producing at least some of our food. Without being connected to the development of the COVID 19 pandemic, this special issue of Social Change Review brings together contributions addressing these thematic areas. It is the result of an international conference - scheduled for April 2020 and cancelled because of the pandemic - that aimed to debate the complex relationship between migration and agriculture at the beginning of the new millennium.

The papers published in this special issue contribute to a rapidly developing area of research, mainly in migration and rural studies, investigating the complex relationship between migration and agriculture. This brief introductory article aims to offer to the reader a context in which to place these contributions within the larger field of migration studies. It also serves the scope of presenting one of the few articulated academic networks

\footnotetext{
*Contact addresses: ymolinero@comillas.edu (Yoan Molinero-Gerbeau)
} 
bringing together scholars interested in issues related to food production, agriculture and migration.

\section{Current intensive agriculture and food processing and the need for cheap seasonal workers}

The launch of the Bracero Program in the 1940s (Mandeel 2014) can be seen as the beginning of the link between migration and modern agriculture. This does not mean that there had been no foreign workers previously doing agricultural work in other contexts. In France, for instance, Spanish and Portuguese labourers worked for decades in the vineyards and, before that, there had been Mexican workers in Californian agriculture, but the Bracero Program marked the first time that a temporary migration programme between two states was articulated for the mass employment of farmworkers.

Since then, the number of migrant farmworkers employed in the countries of the global core has continuously grown (Molinero-Gerbeau 2020). Nowadays, agricultural work in Canada, the United States, Italy, Spain, Australia, New Zealand and Japan cannot be understood without the employment of migrant labour.

Why is this phenomenon taking place? Several dimensions intervene in this process. Understanding the growing 'migrantisation' of agricultural labour in a precise way requires a careful analysis of the social, political and economic dynamics of each enclave (since within the same state there is variation between different territories) but, at an aggregate level, two main groups of factors can be identified: socio-demographic and productive.

At a socio-demographic level, it should be noted that the generalised economic growth of the global core areas implied the expansion of the tertiary sector, as well as of certain industries or sectors such as construction, which caused many workers from rural areas to migrate to the cities for work. Agriculture was thus deprived of a labour force that no longer wanted to do hard work that was poorly paid and had low social prestige (López-Sala 2016) when better alternatives could easily be found. Added to this was the ageing 
of the population, which caused a large part of the traditional agricultural workforce to retire, with no replacement found for them.

At the productive level, this difficulty in finding labour coincided with a generalised process of industrialisation of agriculture (FitzSimmons 1986). Many territories in states such as Spain and Italy, which until the 1980s had a 'traditional' agriculture (peasant and family-owned), chose to follow the path taken by California, where it was shown that by applying Fordist logic, agriculture could offer profits in the millions, equal to those generated by industry. Thus, the peasant model gave way to a more concentrationist one, with large companies acquiring many hectares of land where they could install greenhouses or other elements that would allow intensive production. A clear example of this is in the province of Almería, in Spain, where tens of thousands of plastic greenhouses can even be seen from space (Aznar Sánchez et al. 2014).

The problem encountered by these producers was that, at a time of great need, local labour was no longer available, so they understood that only migration could provide a cheap and reliable labour force to harvest the crops. The models for obtaining these workers varied from one enclave to another and could be divided into three basic types: temporary migration programmes, deregulation and the establishment of large areas of free labour mobility (Molinero-Gerbeau and Avallone 2016).

The first model - temporary migration programmes - refers to initiatives such as the aforementioned Bracero Program, implemented in states such as Canada, Spain, the United Kingdom and New Zealand (among others). These are agreements, usually bilateral, between the state(s) of origin and the state of destination for mass recruitment of temporary workers, whose compulsory return may involve the establishment of circular migrations (Castles 2006).

The second model - deregulation - is characteristic of countries like Italy, whose migration policies produce a constant flow of irregular migrants who, once they arrive at destination, end up being channelled into the underground economy. Agriculture, being a sector where informal logic has 
historically predominated, has been one that provides many work opportunities for these workers, thus implying that employers did not have to ask for a programme as they already had the labour they needed (Avallone 2017).

The third model - the establishment of large areas of free labour mobility - is specific to the European Union as an area of free movement of workers between states with large income differentials. The enlargement of the EU to the East, first in 2004 and then again in 2007, meant that agricultural employers in many enclaves could hire foreign workers without having to go through a programme. States such as the United Kingdom, which has been supplied with agricultural workers from Bulgaria, Romania, Poland (Consterdine and Samuk 2018) and Spain (Şerban et al. 2020) have taken advantage of this context to obtain a workforce.

In parallel to the historical processes described above, a growing research community became interested in analysing the social, political and economic dimensions of this phenomenon. The academic world quickly witnessed how temporary migration programmes, for example, generated new mobilities and dialectics that intersected with broader debates such as development. Both the management of these migrations and the conditions under which these workers worked and lived were investigated in a variety of projects and publications.

However, it is worth noting two great moments in the literature on migration and agriculture: the one produced in the 20th century and that produced in the 21st century.

With regard to the first moment, in the 20th century, it should be pointed out that academic production on the subject was relatively low, as it was a marginal issue within migration studies. Thus, up until the 1990s, publications that can be found are mainly those focusing on the Bracero Program in the United States or in the Canadian context, with the number of research studies produced in other contexts being very small. Without doubt, the writings which had the greatest visibility were those of Calavita (1992) 
and Castles (1986) because of the cross-border impact they had, although the latter did not specialise in the agricultural sector.

It would not be until the 21st century when there was an explosion of publications on the subject, both in long-standing contexts and in those where the phenomenon was becoming more acute. It is no coincidence that, as the presence of migrants grew, the debates that this raised involved an evergrowing academic community.

Today, research production on migration and agriculture is very extensive, although it should be noted that it continues to be a small area within migration studies, despite its exponential growth in recent years. It is no doubt difficult to point out the most outstanding publications on the subject since many have an impact limited to their national contexts, but perhaps we can indicate the literature review done by Rye and Scott (2018) and the books edited by Gertel and Sippel (2014), Corrado, De Castro and Perrotta (2018) and Rye and O'Reilly (2020) as the most complete transnational publications on the subject.

\section{Networking as a way to advance the research}

The growing interest in research on migration and agriculture led to the creation of an international network of academics that warrants mention in this introduction. The year 2013 was crucial for its development for two reasons, the first being the publication in Italian of the book, 'The globalisation of the countryside. Migration and rural societies in the South of Italy' ('La globalizzazione delle campagne. Migrazioni e società rurali nel Sud d'Italia') coordinated by Carlo Colloca and Alessandra Corrado, the first collective manuscript on the subject in Italy. The second, and more important, reason was the organisation of the seminar, 'Agriculture and migration in the European Union' by Domenico Perrotta at the University of Bergamo. This event, which was intended to bring together a small group of Italian researchers (mainly those who had contributed to Colloca and Corrado's book), gradually expanded to take on a transnational dimension due to the 
interest in participating of researchers from Greece, France, the United Kingdom, Spain and, obviously, Italy. This event was key because it brought together researchers from different national contexts, showing that the subject had a high potential for growth and expansion.

The success of this seminar prompted, one year later, in 2014, the 'ENCLAVES' project group of the University of Murcia and, in particular, Elena Gadea, Carlos de Castro and Andrés Pedreño, to organise a second event, this time entitled 'Migrant Labour and Social Sustainability of Global Agri-Food'. The seminar in Murcia included among its participants several of those from Bergamo but also brought new people into the network. Without a doubt, this event was key both to strengthening the fledgling network and to fulfilling another essential function: the future coordinators began to discuss the development of a book, which was eventually published in 2018 by Routledge, entitled 'Migration and Agriculture. Mobility and Change in the Mediterranean Area'.

One year later, in 2015, Apostolos G. Papadopoulos and Maria Loukia Fratsea from Harokopio University in Athens organised the third event in this series of seminars, entitled 'Human Capital, Wage Labour and Innovation in Rural Areas'. As can be seen, the spontaneous nature of this network meant that no seminar repeated the title or indicated any kind of collective identity, but both the organisers and the participants recognised these fora as an annual space in which to strengthen the links and to reinforce research on migration and agriculture.

At the beginning of 2017, organised by Yoan Molinero-Gerbeau and Gennaro Avallone, the fourth seminar took place in Madrid, being the first time that the event was 'numbered', marking its link with the three previous editions. The title of the event was "The 4th International Seminar on Migrations, Agriculture and Food Sustainability: Dynamics, Challenges and Perspectives in the Global Context'. The peculiarity of this seminar (which, like the others, brought a new wave of researchers from new contexts such as Morocco, Poland, Norway and Romania) resided in the hashtag proposed by its organisers to disseminate the activities within networks - '\#agromig' - 
which, informally, would eventually be used by the members as the name of the network.

In 2018, Emmanuelle Hellio, Juana Moreno and Frédéric Décosse took the lead in organising the next annual event of the 'Agromig network'. The '5th International Seminar. Migrations \& Agriculture in the Mediterranean and Beyond' took place in the impressive space of the Musée des Civilisations de l'Europe et de la Méditerranée (MUCEM), in the city of Marseille. This was the seminar that has attracted the most participants to date.

Finally, the sixth, and thus far the last, AGROMIG seminar was organised in 2019 by Mohamed Bouchelka and Yoan Molinero-Gerbeau at the Ibn-Zohr University in Agadir, Morocco. The '6th International Seminar: Migrations, Agriculture, Food and Sustainable Development: Africa and Europe (and Beyond) Facing the New Challenges of Globalization' was the first seminar of the network to take place outside of the European continent, which also served to supply it with a good group of participants from North Africa.

Although AGROMIG is a highly informal network, the links established between its members have become stronger over time, with no lack of annual meetings since 2013 (with the exception of 2016, as the 2017 seminar was organised in January). A substantial number of joint publications, such as the books already mentioned, as well as articles and other collective works, have been published by members of the group during these years.

The next step taken by AGROMIG was to prepare for its seventh seminar in Sibiu, Romania, in April 2020, as an event co-organised in collaboration with the Lucian Blaga University of Sibiu and the Research Institute for Quality of Life, Romanian Academy.

Everything was set up for a new conference, this time advertising the network in the East of Europe - an area where many current migrants working in the EU come from. The idea of making known the work of different scholars on agriculture and migration was also associated with the event: the organisers launched a call for papers for a special issue of the Social Change Review, an open access journal in the field of sociology. 
March 2020, for Europe, was a moment of dire remembering. One by one the countries affected by the COVID 19 crisis started to implement, among other measures, restrictions related to international travel. The conference was suspended, with the idea that, sooner or later, travelling would once again become possible. Unfortunately, all our hopes proved wrong: the pandemic evolved in waves and nobody was able to anticipate what was going to happen. However, while the seminar was to be delayed to a future date when physical meeting would be possible, the organisers decided to continue the work on the special issue. The papers on migration, agriculture, production and consumption of food presented here are the results of the endeavour to ensure the continuity of the AGROMIG network's activities.

\section{Content of the issue}

The four works selected for publication in this themed issue span a rather diverse range of topics, making reference to different geographical areas, different types of agricultural production and patterns of food consumption, from different perspectives. The issue does not aim for unity or homogeneity, but rather to provide/promote distinct (and new, provocative) perspectives and approaches, all of them dealing with the large topic of food production, food consumption and migration.

The paper opening this themed issue, authored by Alexandra Voivozeanu, introduces us in the space of multiple choices that Romanians, as European citizens, face when deciding to migrate. The article offers a hint at the complex system of circulation lying behind European agriculture, which has not yet been sufficiently investigated. It provokes the perspective of the migrant as a 'passive victim' stressing the idea of agency and migrants' active engagement with mobility decisions. The analysis is grounded in qualitative methods, exploring 17 interviews with migrants to different European destinations and three interviews with key informants in one Romanian village. The paper clearly shows that, taking advantage of their freedom to move and work around the EU, Romanians demonstrate a high 
propensity to challenge the paths offered by employers, changing destinations, patterns of mobility (from temporary/seasonal to circular or long-term migration), economic sector of work at destination and entering and exiting the mobility in accordance with their commitments and objectives. The analysis provokes us to understand the precarity that migrant farmworkers face as a result of their limited power of negotiation with their employers, stressing, at the same time, the struggle of individuals to integrate migration into their own lives. The article invites us to reconsider the understanding of migration, and especially of temporary/seasonal or circular migration, as isolated events in migrants' lives rather as being appropriated and shaped by migrants according to their personal goals, objectives and commitments.

The second paper of the issue, Dina Bolokan's article, contributes to the general debate about migrant workers in the European agri-food sector studying the recruitment infrastructure through an analysis focused mainly on the temporary migration of Eastern Europeans to Switzerland and other Western European countries. The theoretical framework facilitates a genealogical understanding of the contemporary recruitment programmes, incorporating references to postcolonial and post-Soviet studies. The reader can find in the article interconnected historical examples of work programmes implemented in Switzerland and EU countries (mainly Germany) derived from the idea of flexible and mobile workers. The concept of hypermobility is presented as a key element of the European agri-food sector and the author argues that this reinforces long-term inequalities and the precariousness of migrant workers' conditions. The analysis is grounded in an extensive fieldwork study conducted between 2011 and 2019 among Eastern European migrant workers and recruiters/mediators within agencies and institutions linked to this system. The analyses include evidence about agricultural traineeship regulations, post-Soviet citizenship practices, bilateral agreements and circular migration policies. Dina Bolokan invites the reader to a deeper reflection upon the driving forces of the migrant workers in European 
agriculture by taking into account the existent regimes controlling migrants' work and mobility.

Irene Peano's study focuses on the use of migrants' farm labour in Italy, as an example of ethno-racialisation at the intersection of food and migration regimes. The author is interested in the development of the system during the last four decades (1980 - present), highlighting the substitution of an internal workforce 'by waves of waged, transnational migrant workers'. The Italian example is discussed within the global dynamics of food production and this allows a general overview on contemporary mechanisms of using a temporary workforce within this complex process, characterised by multiple transformations influenced by 'neoliberal' or 'corporate' features. The author combines various official statistics in order to reveal changes in the use of migrant workers in Italian agriculture from 1980 to the present. The analyses are centred on successive waves of ethno-racialised substitution and distinguish between migrants of African, Eastern European and Asian origins. At the same time, attention is paid to the gender composition of the labour force and to its territorial spread. The author argues that the exploitative practices of the agricultural sector, and Italian immigration policies, produced frequent adjustments of the labour force composition in terms of nationality. When some nationalities obtained new rights on the labour market (for example, nationals of countries that gained EU membership in 2004 and 2007) the agri-food system rapidly reoriented towards other immigrants to fill in the gaps, thus maintaining the precarity and the exploitation.

The special issue is closed by Marinescu and Rodat's comparative study on media representations of food and nutrition in Romania and Germany. The authors build their analysis on the idea that online media content is a reflection of the national society's attention paid to such topics and it also influences individuals' attitudes and opinions in relation to food production and consumption. The article's theoretical framework combines aspects related to the transformation of media content (e.g. tabloidisation) and its influence on the population's health behaviour through information about 
food production and nutrition. The empirical data used within the study are derived from a broader international project, which allows specific comparisons between selected countries. Thematic content analyses were performed on more than 200 online media articles indexed by Google (during the period 1st January 2014 - 1st January 2017) and selected by using similar key words (138 articles in Germany and 80 articles in Romania). The authors' findings about the similarities and (more importantly) the differences between these two countries highlight the idea that, within the EU, different models of discussion about food production and nutrition exist (to select only one relevant example, the article reveals that German online media content about food and nutrition includes multiple references to the sustainability of food production, pollution and other environmental issues, while these topics are almost ignored in articles focused on food and nutrition in Romania). This type of analysis invites the reader to think about the media's role in informing the population about the costs of the contemporary global food system and the intricacies of food consumption and preferences.

\section{References}

Avallone, Gennaro. 2017. Sfruttamento e Resistenze. Migrazioni e Agricoltura in Europa, Italia, Piana Del Sele. Verona: Ombre Corte.

Aznar Sánchez, Jose A., Luis J. Belmonte-Ureña, and Juan J. Tapia-León. 2014. "The Industrial Agriculture: 'A Model for Modernization' from Almería?" In Seasonal Workers in Mediterranean Agriculture. The Social Costs of Eating Fresh, edited by Jörg Gertel and Sarah Ruth Sippel, 293. Abingdon: Routledge.

Calavita, Kitty. 1992. Inside the State: The Bracero Program, Immigration and the I.N.S. New York: Routledge.

Castles, Stephen. 1986. "The Guest-Worker in Western Europe - An Obituary." International Migration Review 20 (4): 761-78.

Castles, Stephen. 2006. "Guestworkers in Europe: A Resurrection?" International Migration Review 40 (4): 741-66.

Consterdine, Erica, and Sahizer Samuk. 2018. “Temporary Migration Programmes: The Cause or Antidote of Migrant Worker Exploitation 
in UK Agriculture." Journal of International Migration and Integration 19 (4): 1005-20.

Corrado, Alessandra, Carlos De Castro, and Domenico Perrotta. 2017. Migration and Agriculture. Mobility and Change in the Mediterranean Area. London: Routledge.

FitzSimmons, Margaret. 1986. "The New Industrial Agriculture: The Regional Integration of Specialty Crop Production." Economic Geography 62 (4): 334-53.

Gertel, Jörg, and Sarah Ruth Sippel. 2014. Seasonal Workers in Mediterranean Agriculture: The Social Costs of Eating Fresh. Edited by Jörg Gertel and Sarah Ruth Sippel. Earthscan Food and Agriculture. London: Routledge.

López-Sala, Ana. 2016. "Induced Circularity for Selective Workers. The Case of Seasonal Labor Mobility Schemes in the Spanish Agriculture." Arbor 192 (777): 1-12.

Mandeel, Elizabeth W. 2014. "The Bracero Program 1942-1964." American International Journal of Contemporary Research 4 (1): 171-84.

Molinero-Gerbeau, Yoan. 2020. “La Creciente Dependencia de Mano de Obra Migrante Para Tareas Agrícolas En El Centro Global. Una Perspectiva Comparada." Estudios Geográficos 81 (288): 1-27.

Molinero-Gerbeau, Yoan, and Gennaro Avallone. 2016. "Producing Cheap Food and Labour: Migrations and Agriculture in the Capitalistic World-Ecology." Social Change Review 14 (2): 121-48.

Rye, Johan Fredrik, and Sam Scott. 2018. "International Labour Migration and Food Production in Rural Europe: A Review of the Evidence." Sociologia Ruralis 58 (4): 928-52.

Şerban, Monica, Yoan Molinero-Gerbeau, and Alexandra Deliu. 2020. "Are the Guest-Worker Programmes Still Effective? Insights from Romanian Migration to Spanish Agriculture." In International Labour Migration to Europe's Rural Regions, edited by Johan Fredrik Rye and Karen O'Reilly, 22-36. Abingdon and New York: Routledge. 